\title{
Electrically-assisted mechanical clinching of AA6061-T6 aluminum to galvanized DP590 steel: effect of geometrical features on material flow and mechanical strength
}

\author{
Abozar Barimani-Varandi ${ }^{*}$ and Abdolhossein Jalali Aghchai \\ Faculty of Mechanical Engineering, K. N. Toosi University of Technology, Tehran, Iran
}

Received: 11 April 2020 / Accepted: 22 August 2020

\begin{abstract}
The mechanical clinching as an alternative joining process for fabricating lightweight aluminum to steel assemblies may face the challenges when joining low-ductility aluminum alloy to high-strength steel. Several researches have been focused on applying the electrically-assisted processes in various fields due to energy efficiency as well as practical simplicity, in order to improve the formability. This paper concentrates on the electrically-assisted mechanical clinching (EAMC) of AA6061-T6 aluminum to galvanized DP590 steel. To this end, a combination of experimental and numerical clinching tests was performed using extensible die at different penetration depths, in which controlling the material flow was obtained by applying newly defined chamfer ratio $R_{C}$ in order to guarantee the strong mechanical interlock. The joint section parameters, failure loads, and failure modes were measured. The effects of the geometrical features on material flow and mechanical strength of clinched joints were analyzed using a FE model. The results showed that the defined parameter $R_{C}$ greatly increased the strength with the use of the EAMC process, which came with a reduction in forming load.
\end{abstract}

Keywords: joining / electrically-assisted mechanical clinching (EAMC) / Al/St joints / material flow / failure load

\section{Introduction}

The widespread use of aluminum alloys in the automotive industry, as the most widely used structural non-ferrous metal, has been increased to reduce emissions and increase fuel efficiency. A $10 \%$ reduction in vehicle weight by replacing lightweight materials will result in a $6-8 \%$ decrease in fuel consumption. However, aluminum alloys are not completely replaceable with steels due to challenges such as cost, performance, and joining problems. Therefore, the hybrid use of aluminum alloys and high strength steel alloys has become an inevitable trend for fabricating lightweight assemblies made in aluminum to steel (Al/St) $[1,2]$.

Among the most commonly used spot joining processes available in manufacturing, the great benefits of mechanical clinching (MC) have made it an ideal process for hybrid $\mathrm{Al} / \mathrm{St}$ assemblies compared with conventional methods including resistance spot welding (RSW), friction stir spot welding (FSSW), and self-piercing riveting (SPR). The RSW is very challenging for the $\mathrm{Al} / \mathrm{St}$ materials owing to different melting points and thermal conductivity [3].

\footnotetext{
* e-mail: Barimani.Abozar@gmail.com
}

Also, more than two similar or dissimilar sheets may be joined in difficulty using FSSW as well as RSW. In addition, the presence of oxide layers for aluminum, the easy formable $\mathrm{Fe}-\mathrm{Al}$ brittle intermetallic compounds, and the blocking wall at the faying surface of surface-treated $\mathrm{Al} / \mathrm{St}$ sheets limit the material flow and heat flow between sheets [4-8]. According to $\mathrm{AWS}^{1}$ D8.1M:2007 standard, the minimum recommended failure load in the tensile shear testing for resistance spot welds of the $\mathrm{Al} / \mathrm{St}$ sheets is calculated by equation (1)

$$
\begin{aligned}
& \mathrm{ST}= \\
& \frac{\left(-6.36 \mathrm{E}^{-7} \times \mathrm{S}^{2}+6.58 \mathrm{E}^{-4} \times \mathrm{S}+1.674\right) \times \mathrm{S} \times 4 \times \mathrm{t}^{1.5}}{1000}
\end{aligned}
$$

where $S$ is the shear strength of the aluminum upper sheet in $\mathrm{MPa}, t$ is its sheet thickness in $\mathrm{mm}$, and the ST is the failure load in $\mathrm{kN}$.

The main obstacle in the SPR is increasing of the structure weight [9]. However, the MC may be used when joining two or more dissimilar sheets such as galvanized, painted or organically plated materials without any

${ }^{1}$ American Welding Society. 
additional part. There are other advantages that indicate the capability of this method for mass production including improved fatigue strength, environment-friendly, low power consumption, no pre-working or reworking required, high tool life, and minimum maintenance costs [10].

The mechanical clinching process which is established in the DIN 8593 standard involves a localized plastic deformation using a relatively simple punch and an anvil, which results in a joint by forming a mechanical interlock. It was firstly patented in 1897 [11]. Audi company reported its mass production in 1985 [12]. Most famous automakers companies have employed the MC joints in various assemblies such as Benz, Ford Motor, Fiat, Porsche, and Suzuki Motor, as well as the aerospace industry, different kinds of household appliances, electrical appliances, ventilation, and air-conditioning products [11-14]. Despite the high flexibility of this process, its joining range for the aluminum alloy to high-strength steel is small because of the low ductility. The limited material flow for lowductility materials causes to failure in MC. Many works investigated the possibility of improving the material flow to create strong interlock using geometrical modifications. To this end, several researches have been performed to investigate the geometry and shape of the anvil to strengthen the joint. The researchers at the Chemnitz University of Technology introduced the one-step flat clinching and created a good interlock, in which the material flowed within the total thickness using the flat anvil [15]. Kim et al. [16] improved the strength of joints by optimizing of clinching tools on the basis of the result of DOE and FEA. Mucha [17] investigated the effect of anvil geometrical parameters on the joinability of advanced high-strength steel using FEM analysis. He reported that the anvil groove width was the most important parameter affecting the material flow in the clinching process using a rigid anvil. Abe et al. [18] clinched the high strength steel to aluminum alloy sheets with dies for control of metal flow. In the joining for the upper high strength steel sheets, the occurrence of neck fracture was prevented by reducing the rigid anvil depth. For the lower steel, the occurrence of cracks in the peripheral material of the anvil-side sheet (bulged bottom) was prevented by eliminating the groove of the anvil. Abe et al. [19], in other work, improved the joinability by the incrementally metal flow with the counter-pressure of the rubber ring in the anvil cavity to join the galvanized ultra-high-strength steel sheets having low ductility. Lambiase [20] optimized the extensible anvil depth in clinching of low-ductility AA6082-T6 sheets, in order to reduce the strain concentration around the punch corner and enhance the material flow. Atia and Jain [21] joined AA7075 aluminum alloy sheets using different temperature conditions by die-less clinching. They used blank holders of different shapes and dimensions to control the material flow. Wang et al. [22] replaced the shape of the anvil groove by a simplified arc curve using the mathematical optimization model. They increased the axial and shear strength of the Al6061-T6 clinched joints by $43 \%$ and $30 \%$, respectively.

In order to comprehensively understand the material flow during the forming of the clinched joint, three phases have been introduced as depicted in Figure 1.

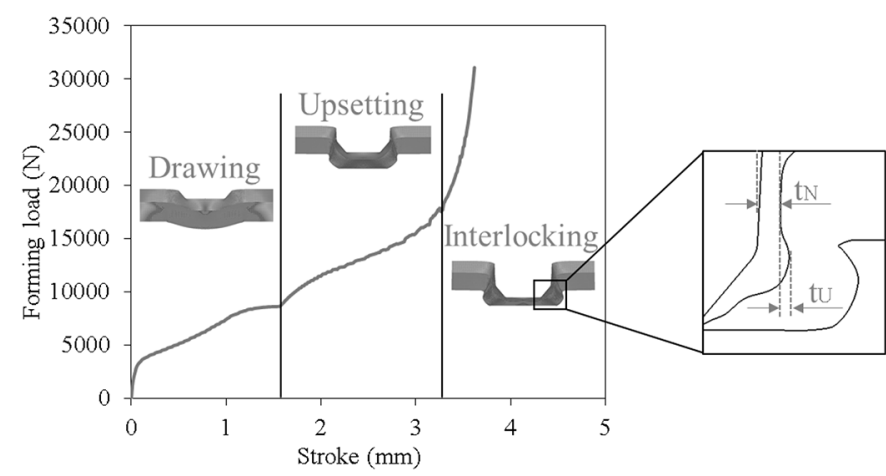

Fig. 1. Three phases of mechanical clinching and joint section parameters.

In the first phase, the punch draws the two sheets into the anvil cavity which resembles the drawing process of bimetal sheets. In the drawing phase, the neck fracture is prone to occur due to the excessive strain concentration in the punch corner zone. Then, the sheets materials are pressed in the anvil cavity, thus flow radially propagates and the bulged bottom diameter increases. Finally, the interlocking phase continues up to the end of the punch stroke. The ease of radial material flow in the second phase results in forming a large interlock. As shown in Figure 1, there are two important parameters in the clinched joint cross-section which are created in the last phase including the neck thickness $\left(t_{N}\right)$ and the produced undercut $\left(t_{U}\right)$. In order to strengthen the clinched joints, it is necessary to maximize the neck thickness as well as the undercut [23]. Literature reviews revealed that no prior attempts have been made to control the material flow with the modification of the punch corner in order to improve the clinched joint strength.

Generally, two failure modes are seen when a joint is fractured by a tensile shear testing. The minor geometrical interlock and small neck thickness may cause the failure of the joints in the button separation (BS) and neck fracture (Neck) modes, respectively. A hybrid failure mode with the combination of button separation and neck fracture may occur when there is a good balance between the undercut length and neck thickness. This mode was observed when there was a little difference between the interlocking strength and the strength of the thinnest created neck. The aforesaid modes have been depicted in Figure 2. The maximum strength of the joints was reported when the hybrid mode, i.e. a combination of shear and tensile failure, was seen [23-26].

Although controlling the material flow is very important in MC, improving the formability is a prerequisite when both clinching sheets having low ductility. Some studies focused on the formability enhancement using heating operation prior, during, and after the clinching including electrical resistance [27,28], induction [29], heater gun [20,30], furnace [31], laser [32], and friction assisted clinching [33,34]. Noticeably, the pre-heating operation dramatically improved formability and reduced the forming load [20]. It is worth noting that the aforementioned heating methods are facing challenges including high energy consumption (electrical resistance and induction), 


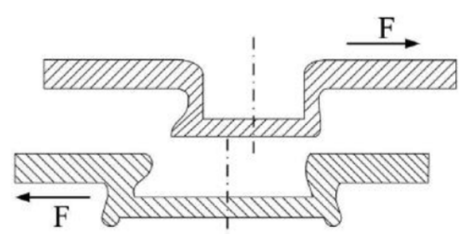

Button separation mode (BS)

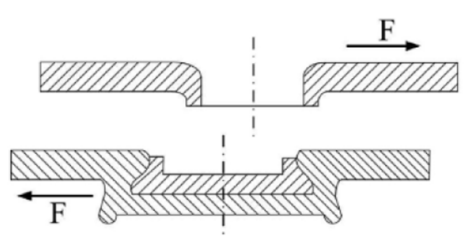

Neck fracture mode (Neck)

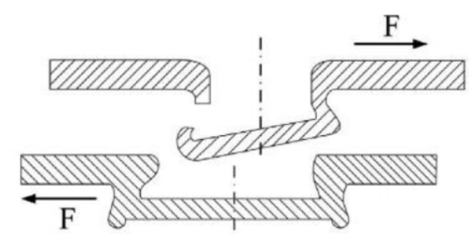

Hybrid fracture mode (Hyb.)

Fig. 2. Three kinds of failure modes for clinched joints in the tensile shear testing.

Table 1. Chemical composition of sheets material (wt. \%).

\begin{tabular}{llllllllllllllll}
\hline & $\mathrm{Ti}$ & $\mathrm{Zn}$ & $\mathrm{Cr}$ & $\mathrm{Mg}$ & $\mathrm{Mn}$ & $\mathrm{Cu}$ & $\mathrm{C}$ & $\mathrm{Si}$ & $\mathrm{P}$ & $\mathrm{S}$ & $\mathrm{Fe}$ & $\mathrm{Ni}$ & $\mathrm{Al}$ & $\mathrm{N}$ & $\mathrm{Sn}$ \\
\hline AA6061 & 0.11 & 0.20 & 0.18 & 0.93 & 0.09 & 0.20 & - & 0.72 & - & - & 0.58 & & Balance & & \\
DP590 & - & - & 0.02 & - & 1.01 & $<0.02$ & 0.09 & 0.28 & 0.01 & 0.01 & Balance & $<0.02$ & 0.04 & 0.01 & 0.01 \\
\hline
\end{tabular}

thermal distortions (convection and flame heating), high initial investment (laser), and low tool life (friction assisted clinching). On the other hand, for the electrically-assisted processes applied in various fields, e.g. FSW, incremental forming, wire drawing, rolling, forging, and sheet metal forming, many advantages were reported such as its ease of manufacture, energy-efficient, and good quality for products $[35,36]$.

In the present study, the electrically-assisted mechanical clinching of AA6061-T6 aluminum to galvanized DP590 steel was studied, which the material of both sheets had less ductility. The main objective of this paper is to improve the strength of the mentioned clinched joint. To this aim, the material flow was controlled by introducing the newly defined chamfer ratio $R_{C}$ which was achieved by reduced strain intensity and ease of radial flow. The geometry of joints, failure loads, and failure modes were investigated. The joint strength was determined based on the tensile shear testing. Furthermore, an integrated 2-step coupled electrical-thermal-mechanical FE model was developed in order to analyze the temperature distribution, material flow, and mechanical strength.

\section{Materials and methods}

\subsection{Materials}

The aluminum alloy AA6061-T6 sheets as the upper material with $1 \mathrm{~mm}$ thickness were joined to anvil-sided DP590 + Z140 with a thickness of $1.5 \mathrm{~mm}$ that was galvanized with coating $275 \mathrm{~g} / \mathrm{m}^{2}$. The chemical compositions of materials have been shown in Table 1.

The uniaxial tensile tests were performed according to ASTM E08 standard, using a universal testing machine model STM-50 equipped with a load cell at a constant speed of $1 \mathrm{~mm} / \mathrm{s}$. An elastic-plastic behavior was described using the stress-strain data up to maximum uniform strain to fit the Hollomon constitutive equation (2).

$$
\sigma=\mathrm{K} \varepsilon^{n}
$$

where $K$ is the strength coefficient and $\mathrm{n}$ is the strainhardening exponent. Their values have been reported in Table 2.

The increase in elongation indicates higher material formability under the EAMC condition, compared with the no-preheating mode which was performed at room temperature (RT). It can be noted that the tensile drawing speed was equal to the clinching punch speed, so the effect of strain rate especially for the EAMC was reduced. According to the importance of strain rate effect on material behavior at elevated temperatures $[37,38]$, the similar punch speed was applied in uniaxial tensile test compared to clinching process. It should be noted that contrary to tensile test, various strain rates are created during clinching process. However, the same punch speed applied in both tensile test and clinching process, can reduce the strain rate effect on material behavior. So, the material property inserted to $\mathrm{FE}$ model may be more accurate for the simulation.

The geometry of joints was assessed by capturing the cross-sections (cut near the diametric plane) using a $35 \mathrm{~mm}$ SLR lens on Canon EOS $1300 \mathrm{D}$ mounted on an optical microscope model IM7200 by MEIJI TECHNO. Tensile shear testing were performed to determine the mechanical strength of the joints under quasi-static condition (constant crosshead speed of $2 \mathrm{~mm} / \mathrm{min}$ ), according to ISO 12996. The sheets were cut using wire cutting machine. Two pads were used at both sides of the specimen to prevent any moment around the clinched joints. For each test condition, five repetitions were performed. Figure 3 shows the geometry of the test specimen used in these tests. The rolling direction was parallel to the sheets length. 
Table 2. Mechanical properties of the sheets material.

\begin{tabular}{llllllr}
\hline Mat. & Condition & $\begin{array}{l}\text { Yield strength } \\
(\mathrm{MPa})\end{array}$ & $\begin{array}{l}\text { Tensile strength } \\
(\mathrm{MPa})\end{array}$ & $\begin{array}{l}\text { Elongation } \\
(\%)\end{array}$ & $\begin{array}{l}\mathrm{K} \\
(\mathrm{MPa})\end{array}$ & $\mathrm{n}$ \\
\hline AA6061 & RT & 275 & 325 & 16 & 477 & 0.1245 \\
AA6061 & EAMC(500 A) & 191 & 277 & 34 & 510 & 0.2880 \\
DP590 & RT & 402 & 645 & 20 & 1047 & 0.1889 \\
DP590 & EAMC(500 A) & 351 & 597 & 25.5 & 1002 & 0.2098 \\
\hline
\end{tabular}

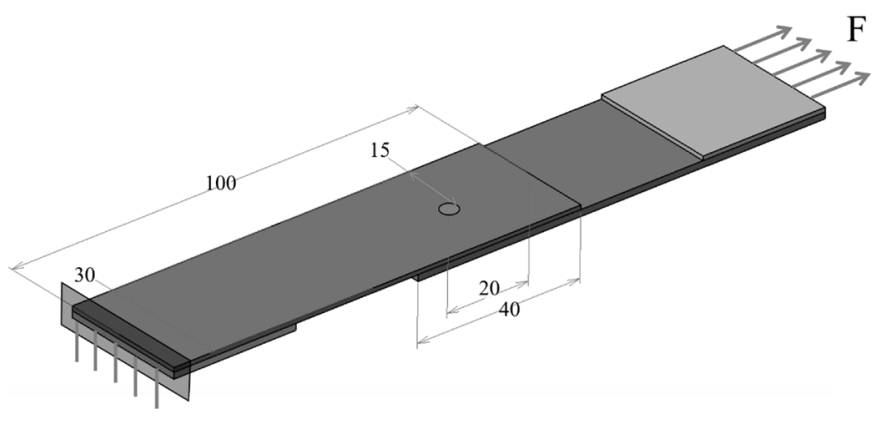

Fig. 3. Dimensions of the test specimen used in tensile shear testing.

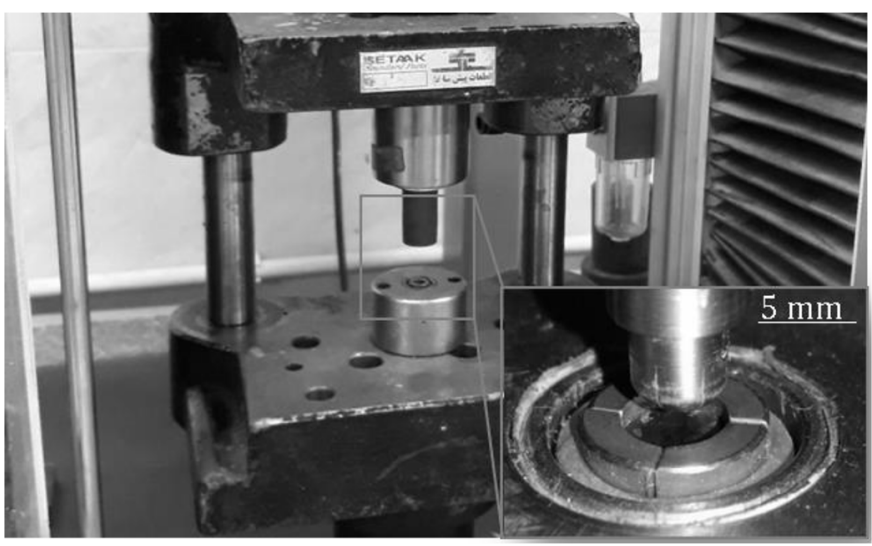

Fig. 4. Clinching process die setup.

\subsection{EAMC equipment}

A conical-shaped punch with a half-angle $3^{\circ}$ was used. The initial diameter of the punch head assumed $4.6 \mathrm{~mm}$. The extensible sectors with the same internal diameter $5.6 \mathrm{~mm}$ and anvil depth $1.3 \mathrm{~mm}$ were employed. To relieve the strain concentration, the sharp edges converted to round corners with $0.2 \mathrm{~mm}$ radiuses. These dimensions were selected according to the literature review [18,39-41]. In addition, two chamfering punches with a length of $0.65 \mathrm{~mm}$ and $1.30 \mathrm{~mm}$, at the constant angle $45^{\circ}$, were used. The clinching process was performed with the tools mounted on the two guiding upper and lower shoes. The clinching apparatus has been shown in Figure 4, while the characteristic dimensions of the extensible die, made of warm working hardened steel (DIN 1.2344), have been depicted in Figure 5.

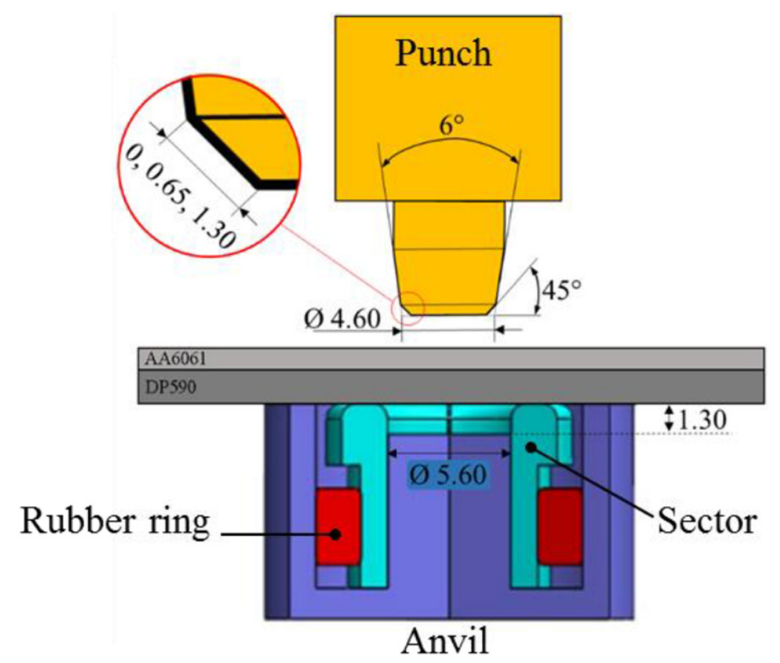

Fig. 5. Main dimensions of the clinching tools ( $\mathrm{mm})$.

The four sectors surrounded the anvil could slide radially which were balanced by a rubber ring. The blank holder had a stiffness of $280 \mathrm{~N} / \mathrm{mm}$. The punch speed was set to $1 \mathrm{~mm} / \mathrm{s}$. A dedicated fixture was designed for the electrically-assisted mechanical clinching of aluminum alloy AA6061 to DP590. The electrically-assisted equipment consisting of the mentioned components has been shown in Figure 6.

As depicted in Figure 6, to perform the EAMC process, a groove was machined on the top surface of a backplate for positioning the sheets during the pre-heating operation. The sheets were electrically insulated from the fixture structure and die shoes using the thin layers of mica film, to reach the maximum current density. The electrical current was applied only for pre-heating thus was turned off priorly the punch started to touch the upper sheet. During preheating operation, the temperature variations of upper and lower sheets were measured and monitored using two K-type thermocouples placed on the exposed and on the opposite surface of the joint center. Prior to pre-hating operation, the sheets were degreased by acetone to avoid burning oil/grease while heating. After pre-heating, the punch was rapidly moved to produce the joint and then the punch was retracted.

The current was applied only for pre-heating thus was turned off prior to touching of upper sheet by punch.

The pre-heating operation was performed with the alternating electrical current. The applied current flowed 
through the sheets using two copper electrodes. Each one was pressed on the top surface of the sheets through equal distance from the joint center. The electrical current could be varied manually via using autotransformer on the input line. A digital clamp meter was used for monitoring the electrical current. The mica films were used to insulate the accessories from the press bed. The system was capable of setting a current about $500 \pm 5 \mathrm{~A}$. This value was used in all the experiments at a pre-heating duration time of $50 \mathrm{~s}$ under an operating potential of $3 \mathrm{~V}$. The choice of the longer duration for pre-heating operation was mainly limited by the overheating problem. The maximum created temperature at AA6061 and DP590 sheets were $135^{\circ} \mathrm{C}$ and $159^{\circ} \mathrm{C}$, respectively.

\subsection{FE model}

In addition to experimental studies, an integrated 2-step FE model, created using DEFORM V11 multiple operations interface, was used to investigate the results that were costly, even inaccessible, and experimentally difficult to obtain. It is noteworthy that the main objective of the numerical study was to gain a better understanding of the clinching experiments. A numerical model of the process was used to simulate the coupling between electrical and thermal phenomena and between the thermal and mechanical phenomena provided by commercial FE software. Although the mechanical clinching using a round

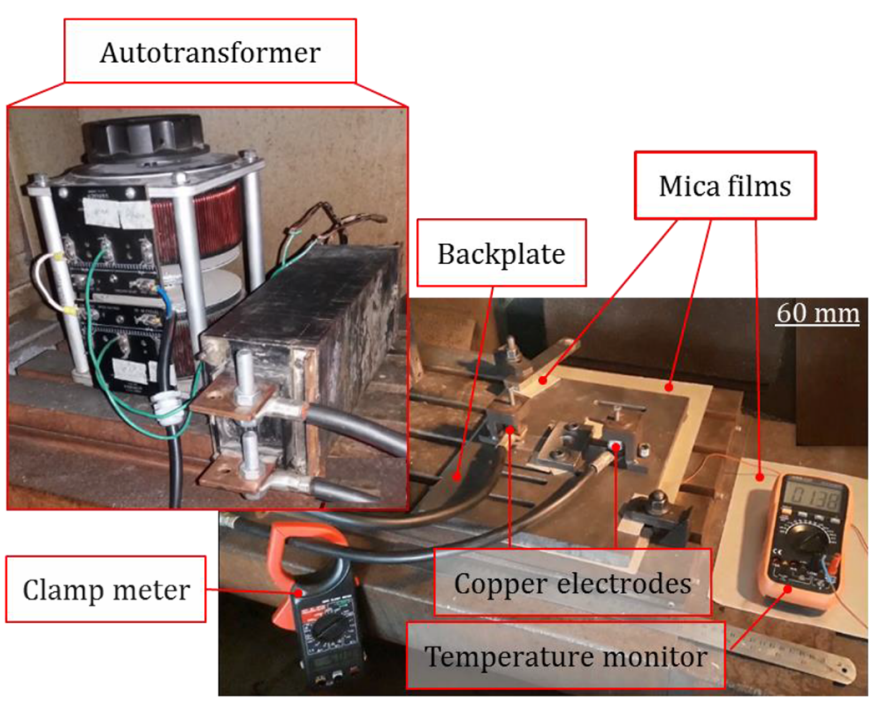

Fig. 6. Electrically-assisted equipment.

tool type can be modeled with an axisymmetric assumption, the pre-heating operation using two copper electrodes on either side of the joint center invalidates this assumption. Therefore, a 2D plane strain model was used to effectively simulate the process. The schematic of each step including the boundary conditions has been shown in Figure 7.

In the first step, the resistance pre-heating operation as an electrical-thermal problem was simulated. The second step was continued by exerting the extensible dies, as a thermal-mechanical problem. The process history resulted in each step was converted to the next one. The initial temperature of the whole model was set at $25^{\circ} \mathrm{C}$ for the first step. The electrical loading scheme was given using copper electrodes with the aforementioned current magnitude, and then Joule heating was provided. The Thermophysical properties of sheets have been reported in Table 3 .

After completion of the electric loading, the second step was continued by replacing the punch, blank holder, sliding sectors, and anvil. The anvil was assumed to be fixed, while the punch followed a prescribed displacement equal to penetration depth. The blank holder forced was replaced with stiffness and displacement. The movements of the sliding sectors were depended on the predefined preload. When the force exceeds the preload value, the sliding sectors begin to move under the spring load control. The preload value was assumed to equal $10 \mathrm{~N}$ since is usually negligible in the clinching process. Each simulation was thus stopped as the penetration depth of the punch reached the experimental prescribed value.

Linear 4-node tetrahedral elements were adopted for discretization. The element length varied from $0.01 \mathrm{~mm}$ up to $0.5 \mathrm{~mm}$. In order to avoid severe local mesh distortions, a finer mesh was used in regions by high local plastic strains. The automatic remeshing technique was applied to prevent the distortion of the elements. In addition, because of the high contact pressure between the sheets, a modified

(a)

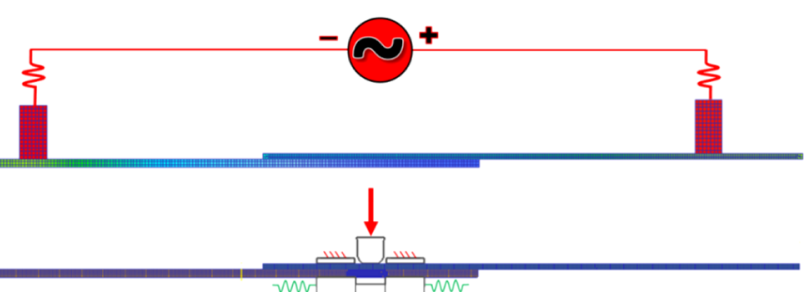

Fig. 7. Schematic of the 2-step numerical model: (a) pre-heating operation, (b) clinching process.

Table 3. Physical and thermal properties of sheets material.

\begin{tabular}{lllllc}
\hline Material & $\begin{array}{l}\text { Density } \\
\left(\mathrm{kg} . \mathrm{m}^{-3}\right)\end{array}$ & $\begin{array}{l}\text { Young's } \\
\text { modulus } \\
(\mathrm{GPa})\end{array}$ & $\begin{array}{l}\text { Poisson's } \\
\text { ratio }\end{array}$ & $\begin{array}{l}\text { Specific } \\
\text { Heat } \\
\left(\mathrm{J} . \mathrm{kg}^{-1} \cdot{ }^{\circ} \mathrm{C}^{-1}\right)\end{array}$ & $\begin{array}{l}\text { Conductivity } \\
\left(\mathrm{W} \cdot \mathrm{m}^{-1} \cdot{ }^{\circ} \mathrm{C}^{-1}\right)\end{array}$ \\
\hline Steel & 7800 & 205 & 0.3 & 450 & 50 \\
AA6061 & 2700 & 70 & 0.33 & 920 & 190 \\
Copper & 8900 & 130 & 0.33 & 390 & 400 \\
\hline
\end{tabular}




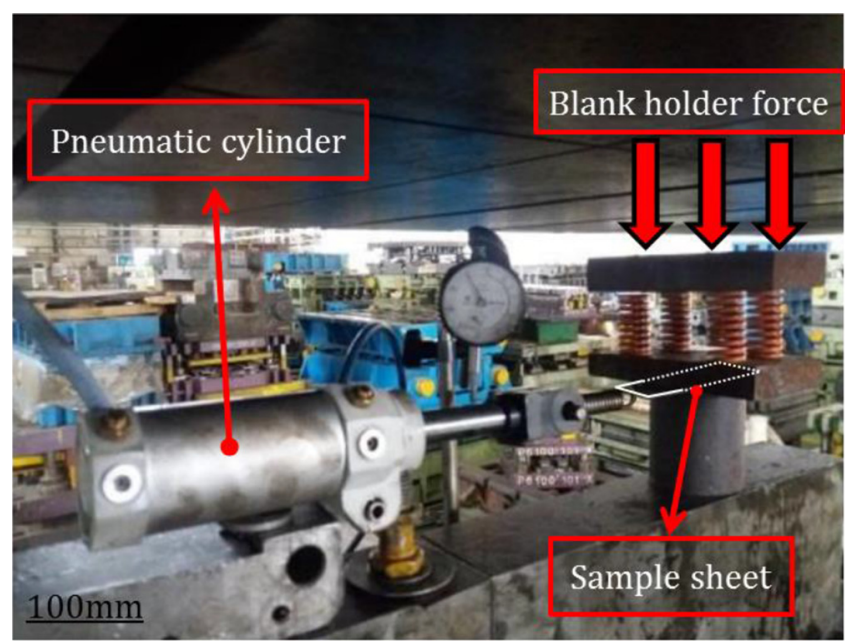

Fig. 8. Coulomb friction test setup.

Table 4. Friction coefficients obtained by Coulomb friction tests.

\begin{tabular}{lll}
\hline Condition & Tool-St & Tool-Al \\
\hline No pre-heating & 0.18 & 0.21 \\
EAMC & 0.19 & 0.26 \\
\hline
\end{tabular}

Coulomb friction model was adopted with a maximum shear stress limit to apply the mechanical interactions [42]. In which subsurface shearing between adjacent sheets occurs when the limit is exceeded. The shear stress limit is expressed by equation (3)

$$
\tau_{\max }=\frac{\sigma_{Y}}{\sqrt{3}}
$$

where $\sigma_{Y}$ is the yield stress of the material with the lower mechanical strength. As depicted in Figure 8, Coulomb friction tests were performed at each condition to find the right Coulomb coefficients for the tool-sheet interface to insert in the FE model [2].

The friction coefficients $(\mu)$ for the tool-sheet interface reported in Table 4, were calculated using Coulomb friction law.

For each simulation, the blank holder force was exerted vertically. Then, the pneumatic cylinder guaranteed the required horizontal force $(F)$ to start the blank motion. The coefficients of friction for the sheet-sheet interface under the sticking condition were assumed 0.50 for no preheating mode and 0.55 for the EAMC [43]. Also, the thermal and electrical conductance values at interaction were considered equal to $20 \mathrm{~mW} \mathrm{~mm}^{-2}{ }^{\circ} \mathrm{C}^{-1}$ and $0.2 \mathrm{~m} \Omega^{-1} \mathrm{~mm}^{-2}$, respectively. The convective heat transfer coefficient was inserted $20 \mathrm{~W} \mathrm{~m}^{-2}{ }^{\circ} \mathrm{C}^{-1}$ [44].

\section{Results and discussion}

\subsection{Clinch-ability window}

In order to determine the clinching locus, the penetration depth $(P)$ was changed with the increments of $0.1 \mathrm{~mm}$.

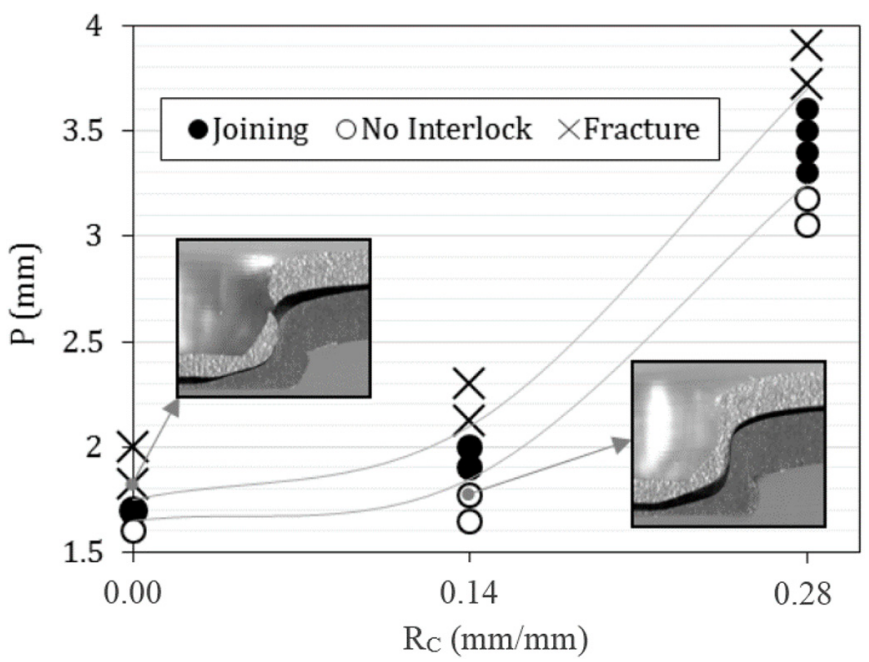

Fig. 9. Clinch-ability window for various $R_{C}$ values.

The clinch-ability window obtained from the experiment has been plotted in Figure 9.

As shown in Figure 9, the experiments using initial punch just created a small undercut (less than $0.1 \mathrm{~mm}$ ) at the $P$ equal to $2 \mathrm{~mm}$, because of the insufficient material flow between the corners of the punch and anvil. The higher $P$ values caused the fracture at the upper sheet resulted from strain concentration at the region in contact with the punch corner. According to Lambiase [45] and Kim et al. [16], the clinched joint is influenced by the punch corner which directly affects the parameters $t_{N}$ and $t_{U}$. Accordingly, the material flow of the sheets was controlled by modification of the punch corner to create a large undercut which guarantees the strong mechanical interlock. A new dimensionless parameter $R_{C}$ (the ratio of chamfer length to punch diameter) was defined that can help to quantify the effect of the punch corner on material flow. It should be noted that the test with the chamfer length of $1.40 \mathrm{~mm}$ $\left(R_{C}=0.3\right)$ led to the early fracture once the punch touched the upper sheet due to the severe stress concentration at punch nose.

As shown in Figure 9, the punch with $R_{C}$ value of 0.28 created more sound joints than two other ratios. However, the higher exerted $P$ values for $R_{C}$ equal to 0.28 require a higher forming load which, in turn, increases the energy consumption of the joint process. The $R_{C}$ equal to 0.14 caused a $57 \%$ improvement in undercut length compared with the sharp-edged punch. The best interlock which can guarantee a strong joint was created by $R_{C}$ equal to 0.28 , since it led to the increase more than twice the $t_{U}$ compared with the no-chamfer punch.

\subsection{FE model verification}

The developed FE model was verified for both 2 steps, i.e. pre-heating operation and clinching process. To validate the first step, the temperature variation experimentally measured (Ex.) on the exposed and on the opposite surface of the joint center in terms of pre-heating time has been reported in Figure 10. 
Through the joint center, the top surface of the aluminum sheet and the bottom surface of the steel sheet were named $\mathrm{ToAl}$ and BoSt, respectively. The experimental result is the average of three replicates. The numerical temperatures of $\mathrm{ToAl}$ and BoSt, at the end of the pre-heating operation, were predicted higher than the experimentally measured ones by the maximum difference of $9 \%$. It can be due to thermal conduction to fixture structure (resulted of deficiency in insulation), the convective heat transfer with the environment, and ignoring the galvanized coating in FE simulation.

The main defects of the clinching process are the neck fracture, no interlocking, and the micro/macro cracks. The sheets which were jointed successfully in the safety area of the clinch-ability window (between the upper and lower boundaries) were not affected by two former defects. As a result, ignoring the phenomenon of damage in the $\mathrm{FE}$ model for the second step may not cause significant errors in numerical results. As depicted in Figure 11, a similar shape and deformation mode were numerically predicted as well as an acceptable difference in the trend of forming load variation which confirmed the accuracy of the FE model for the clinching process.

As was reported, the FE model overestimated the forming load variation. Such a difference may address some

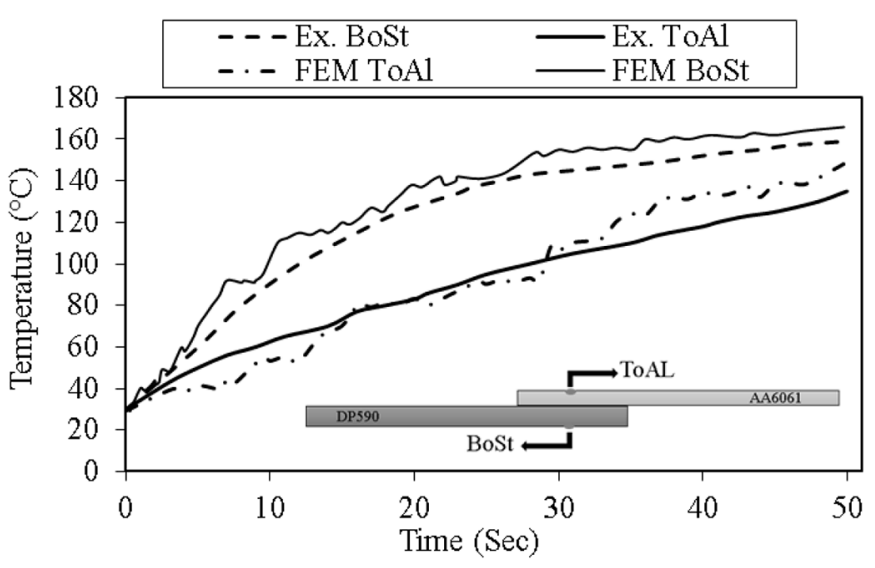

Fig. 10. Temperature variation for the surface of ToAl and opposite surface of BoSt during pre-heating operation. causes including the adoption of the 2D plane strain model, ignoring the material anisotropy, and neglecting the damage in the FE model. However, the main reason for the overestimation of the forming load was the influence of the unpredicted cracks and micro defects which numerically increased the required load capacity. It is expected that the overestimated numerical loads predict thinner necks and larger undercut dimensions. Nevertheless, the error of the FE model can be retained acceptable according to the well accurately reported results.

\subsection{Prediction of temperature variation}

The temperature distribution contour, after pre-heating operation, can be seen in Figure 12.

It is clear that the temperature of the anvil-sided of the joint center rises by a higher rate compared with aluminum side. The higher electrical resistivity of the steel side leads to more temperature compared with the aluminum side. It should be noted that the lower distance between two electrodes can cause more heat at less duration time. The significant rise in temperature especially for the lower sheet in Figure 12b, just after $10 \mathrm{~s}$, confirms the high efficiency of the EAMC process. Nevertheless, the almost similar maximum temperature at the lower sheet $\left(\sim 160^{\circ} \mathrm{C}\right)$ was obtained at a duration equal to 50 s [20], i.e. 5 times more than the EAMC. Noticeably, the higher the electrical current and the closer electrode distance can generate much heat at much slower times. However, assembling problems of the fixture components and the clinching tools positioning, limited the empirical feasibility of the closer distance between electrodes.

\subsection{The effect of material flow on joint section geometry}

Incorrect design of punch as well as the reduced ductility of AA6061 (as the punch-sided sheet) may result in failures involving small interlocks either excessive thinning of the upper sheet. The former was studied numerically using flow velocity, and the latter with strain distribution. The numerical material flow of joints created by various chamfer ratios has been highlighted in Figure 13.

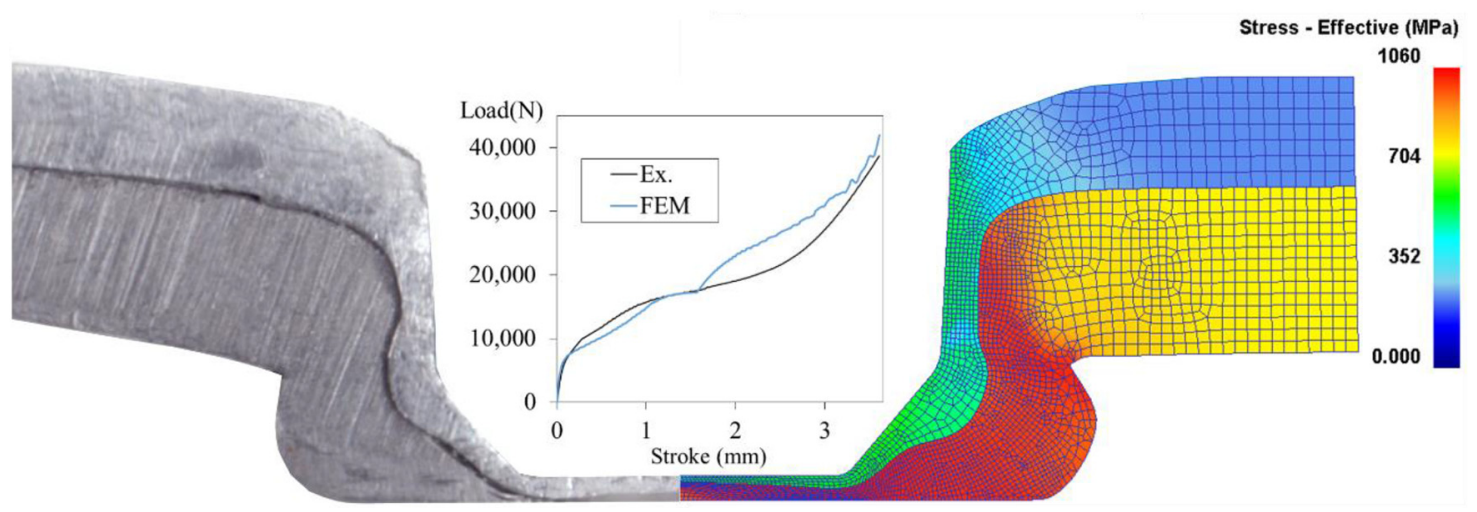

Fig. 11. Comparison of experimental and model cross-section at $\mathrm{P}=3.6 \mathrm{~mm}$. 


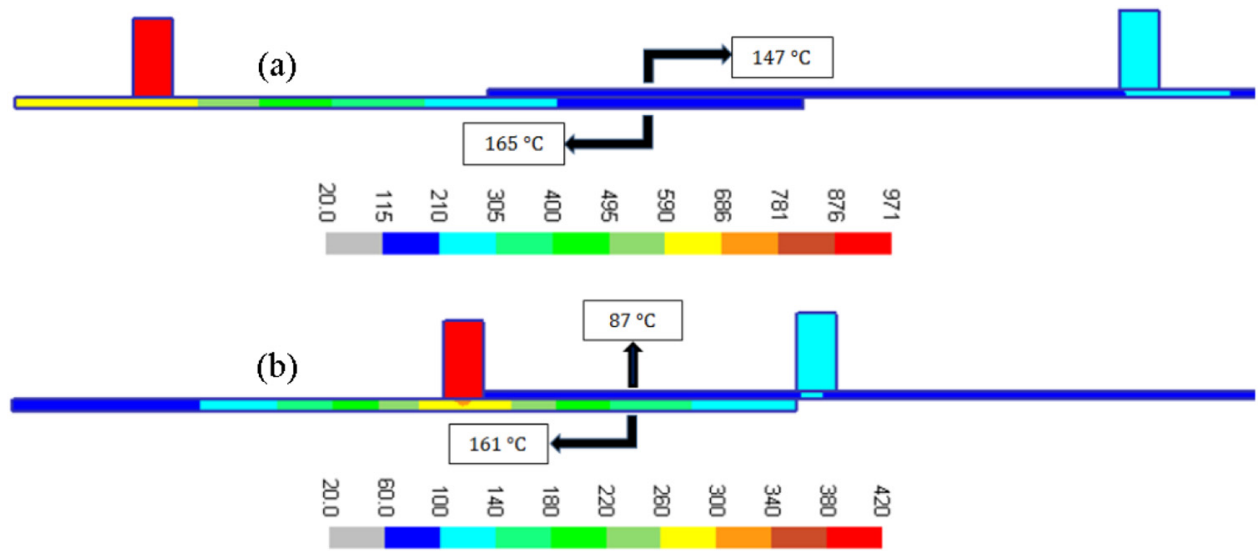

Fig. 12. Temperature distribution contour after: (a) $50 \mathrm{~s}$ pre-heating with electrode axis distance $125 \mathrm{~mm}$ and (b) $10 \mathrm{~s}$ pre-heating with distance $45 \mathrm{~mm}$.

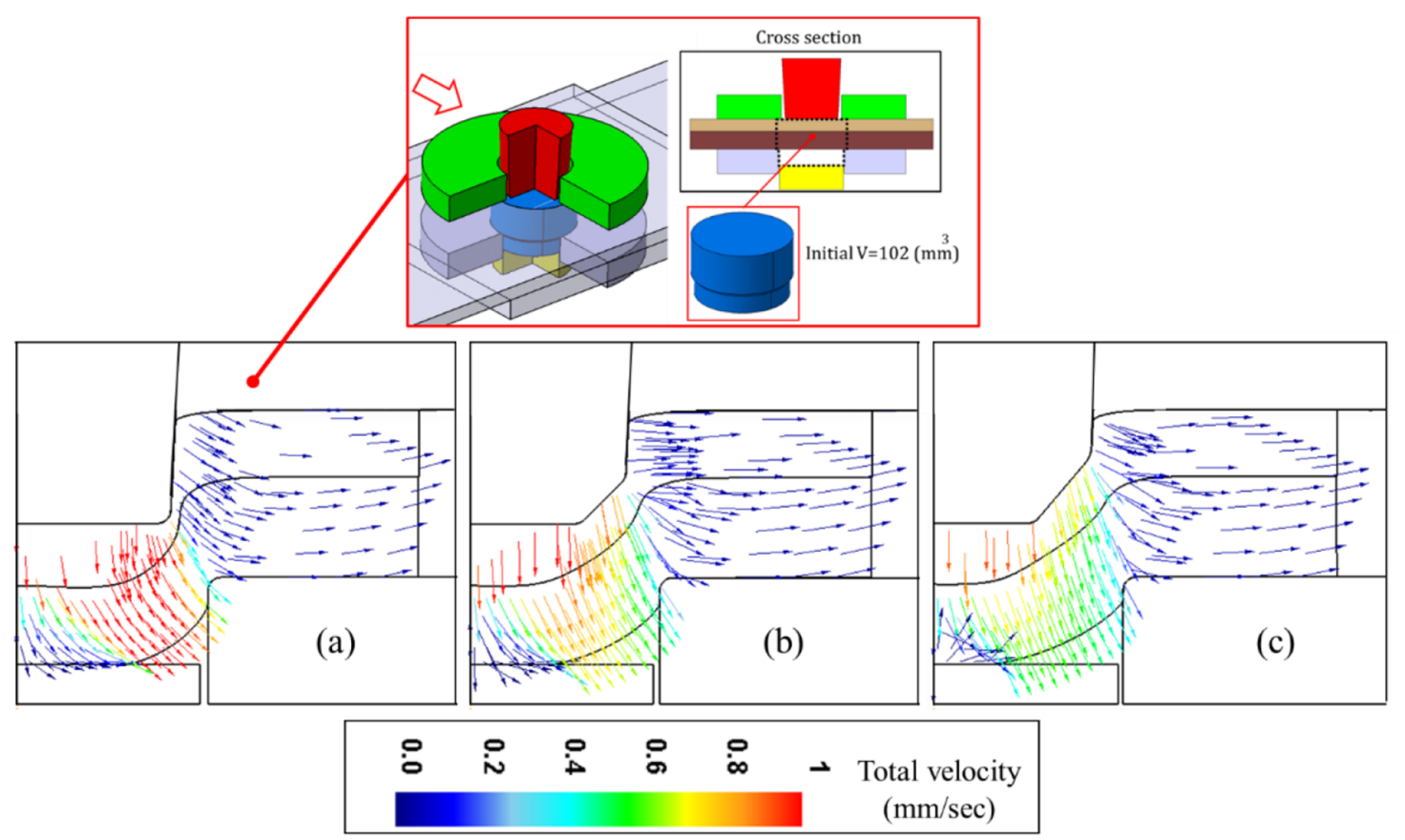

Fig. 13. Temporary flow velocity at $\mathrm{P}=1.7 \mathrm{~mm}$ for various $R_{C}$ values: (a) 0.00 , (b) 0.14 , and (C) 0.28 .

As depicted in Figure 13, all the joints are illustrated at the $\mathrm{P}$ equal to $1.70 \mathrm{~mm}$ to investigate the effect of chamfer length on material flow. This value $(1.70 \mathrm{~mm})$ is equivalent to the maximum allowed penetration of no-chamfer punch before the failure. The increase in the chamfer ratio comes with an increase in the punch-anvil cavity's initial volume. This increase was equal to $1 \%$ and $5 \%$ for the $R_{C}$ values of 0.14 and 0.28 , respectively. This increase means that there is enough space to draw the upper sheet into the radial direction. Consequently, the material flow resistance was decreased since it caused the easiness of material flow and created the uniform flow. This can be observed in the material flow contour of the region under the punch with $R_{C}$ value of 0.28 , where all the various colored vectors were distributed uniformly with the minimum velocity gradient. In contrast, the higher momentary material velocity was created for the $R_{C}$ value of zero, where the punch-anvil cavity volume was less than two other chamfer ratios. The larger velocity gradient which was represented by the multiple red and blue vectors with the maximum and minimum velocity values, respectively, implies a high resistance to the material flow for no-chamfer punch. For the joint created by the $R_{C}$ value of zero, due to the insufficient volume, the material flow especially for the region under the punch directed in the axial direction with the deviation to the outer corner of the lower sheet. However, as the punch-anvil cavity volume increased, the material showed a greater tendency to flow radially which increased the possibility of forming the large undercut. Therefore, the stronger interlock which was created for the $R_{C}$ value of 0.28 can be justified by the easiness of radial flow obtained by increased punch-anvil cavity volume, 


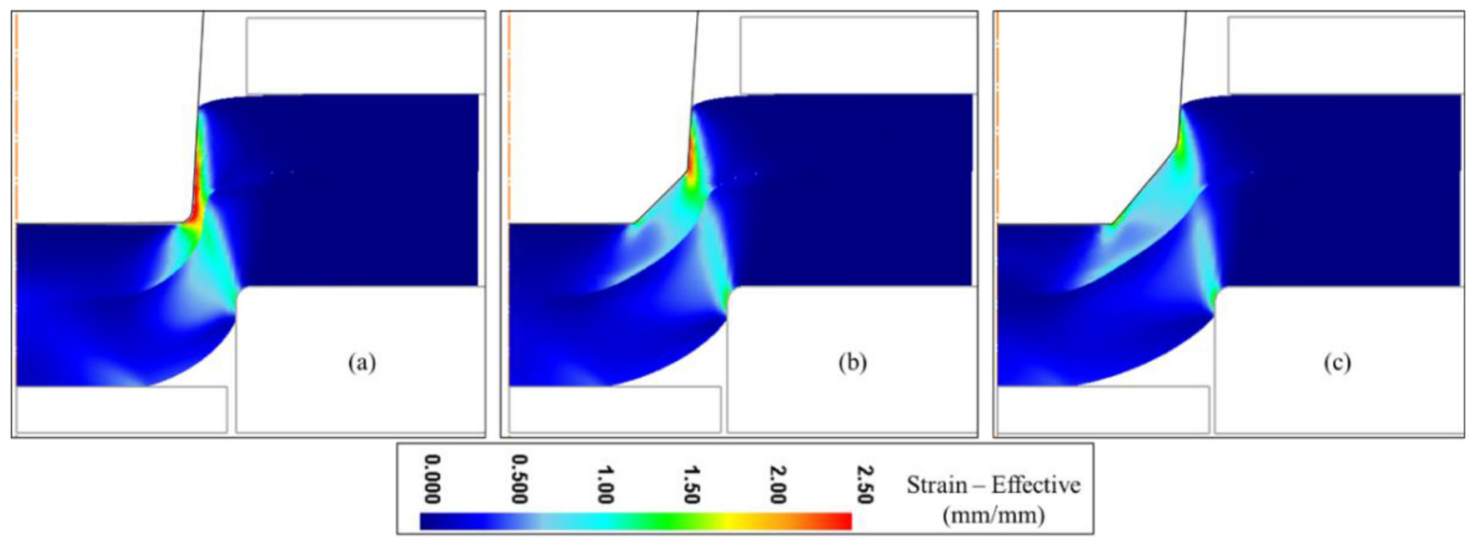

Fig. 14. Strain distribution at $\mathrm{P}=1.7 \mathrm{~mm}$ for various $R_{C}$ values: (a) 0.00 , (b) 0.14 , and (C) 0.28 .

which is in good agreement with the conclusions of literature [20,21].

The other defect in the clinched joint, i.e. the fracture of the upper sheet at the punch corner, was studied by numerical stress distribution. In Figure 14, from the strain distribution point of view, the influence of the chamfer ratio on the strain distribution has been predicted.

The excessive localized strain intensity, at the region in contact with the corner of no-chamfer punch, created a zone prone to failure. This excessive strain experimentally led to the occurrence of fracture for the upper sheet at $P$ equal to $1.8 \mathrm{~mm}$. The larger chamfer ratios reduced the strain intensity, particularly for the $R_{C}$ value of 0.28 . The reduced resistance to material flow for this ratio, derived from higher punch-anvil cavity volume, allowed more uniform strain distribution. In Figure 15, the load changes for the joints depicted in Figure 14 have been shown.

The graphs show that the clinching second phase for all $R_{C}$ values was incomplete and the interlocking phase did not happen at all. By the way, the maximum forming load was reduced by $8 \%$ and $13 \%$ by using the $R_{C}$ values of 0.14 and 0.28 , respectively. These results were consistent with the changes in strain intensity. It is important to note that, the prolonged drawing phase, particularly for the $R_{C}$ value of 0.28 , assisted and facilitated the radial material flow during upsetting and interlocking phases, which was a requisite for creating a strong interlock. The largest undercut created for the clinched joint at the aforementioned EAMC condition has been shown in Figure 16.

The maximum measured undercut was created at a lower forming load compared with no pre-heating mode. The $30 \%$ decline in the maximum forming load can be addressed in two aspects. The first, as expected, was due to the reduction of material flow stress (see Tab. 2), particularly for aluminum side. The other aspect was the lower $P$ value which was applied for EAMC process $(3.2 \mathrm{~mm})$. During the pre-heating operation, although higher temperatures were created at the steel side, the maximum created temperature was about $10 \%$ of its melting point (degree centigrade). Nevertheless, the maximum created temperature was about $20 \%$ of the melting point for aluminum sheet, which had a sensible effect on the material flow stress

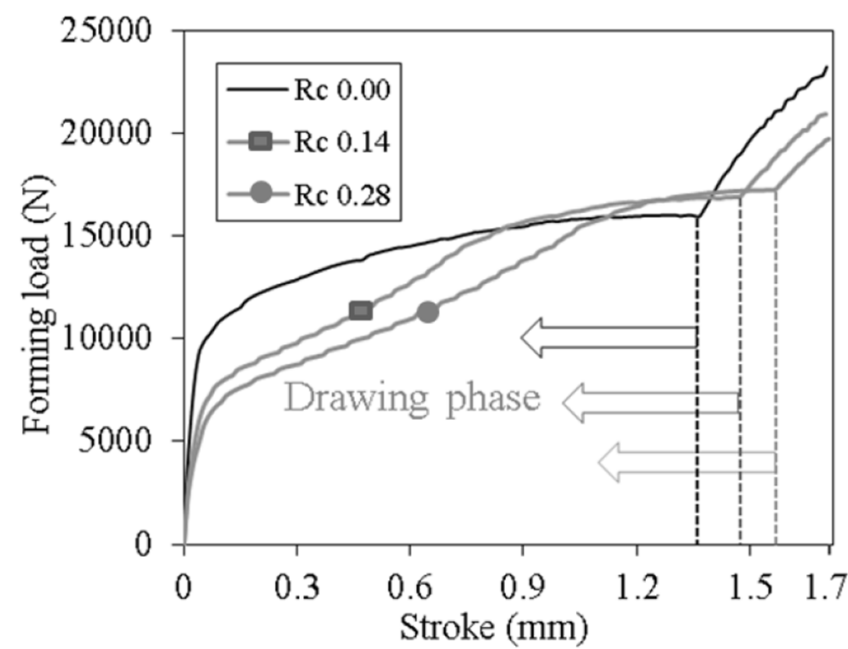

Fig. 15. Forming load variations for various $R_{C}$ values up to $\mathrm{P}=1.7 \mathrm{~mm}$.

of punch-sided material. On the other hand, it did not have much effect on the material flow of the anvil-sided sheet. At the mentioned EAMC condition, the difference in flow stress between the two sheets was increased and consequently affected the material flow. So that, the anvil-sided material forced the upper sheet to flow in the reverse axial direction, i.e. opposite to punch movement like the backward extrusion. This phenomenon which was resulted from using dissimilar materials with different flow stress could not provide the radial material flow. As a result, it caused the drawing phase to be completed prematurely; thus the ease of radial material flow for other phases was limited, as was predicted numerically in the velocity contour of Figure 16. As can be noted, the premature drawing phase induced a smaller thinning neck compared with no pre-heating mode.

\subsection{The effect of the joint section on mechanical strength}

The stress distribution for numerical clinched joints with the largest undercut in each condition has been shown in Figure 17. 


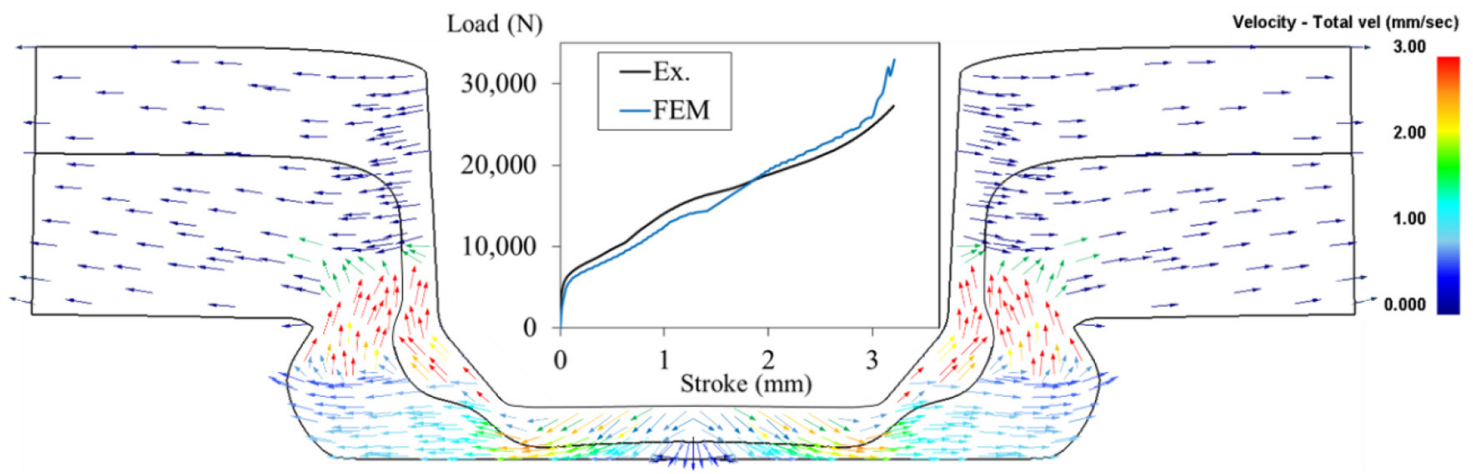

Fig. 16. FE model cross-section at $\mathrm{P}=3.2 \mathrm{~mm}$ for pre-heating mode.

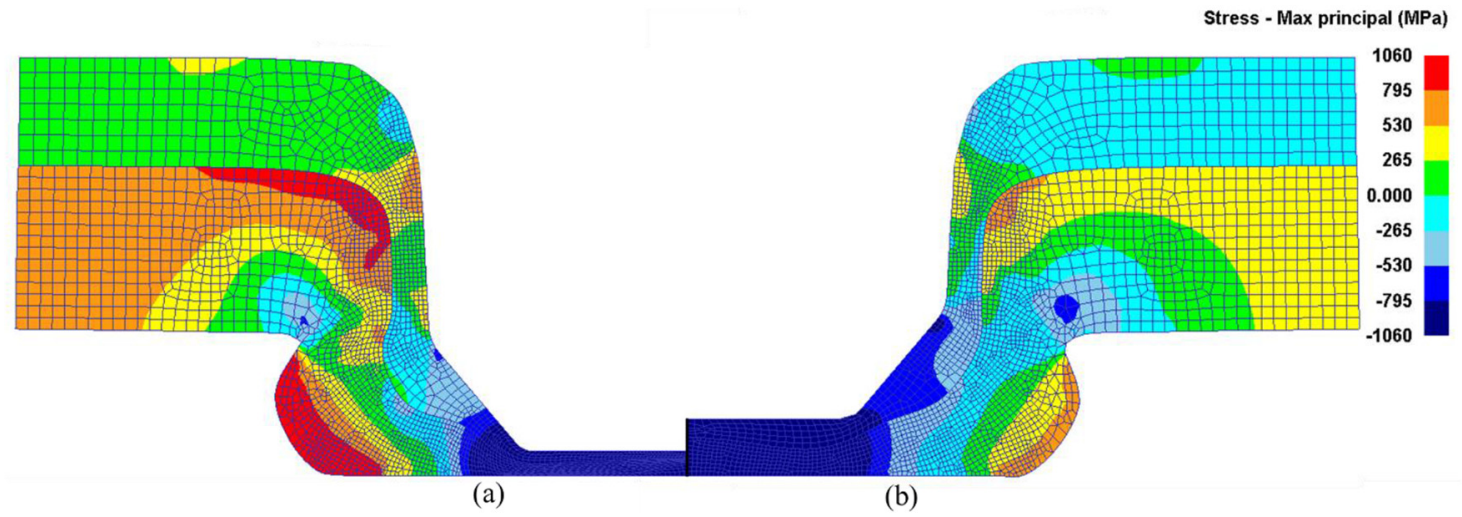

Fig. 17. Comparison of the tensile stress distribution for $R_{C}$ value 0.28: (a) no pre-heating mode with $\mathrm{P}$ value of $3.6 \mathrm{~mm}$ and (b) EAMC with $\mathrm{P}$ value of $3.2 \mathrm{~mm}$.

As predicted in Figure 17, the high magnitude of tensile stress at the bulged bottom can lead to the occurrence of micro/macro cracks. These cracks may not affect the static strength, whereas the fatigue strength and fretting corrosion can be affected particularly under the dynamic loading. One of the main merits of the clinching process in terms of strength is the comparable fatigue strength over the resistance spot welding which is the most widely used spot joining process [46-50]. Therefore, eliminating the macro cracks as well as reducing the micro ones are so important challenges in the clinching process to strengthen the fatigue strength. The smaller magnitude of tensile stress at the bulged bottom at EAMC condition compared with no pre-heating mode shows the ability of the preheating operation in reducing the micro/macro cracks. The bulged bottom images obtained from experimental joints have been shown in Figure 18.

As shown in Figure 18, reducing the defects can be verified where the surface of the bulged bottom for EAMC mode was more continuous and approximately devoid of any macro cracks. Of course, it should be borne in mind that the reduced residual stress obtained by pre-heating operating at EAMC mode, affects the work hardening which can weaken the joint [51].

The variations of joint section parameters as well as experimental failure loads have been plotted in Figure 19. The maximum failure loads are the average peak value of (a)

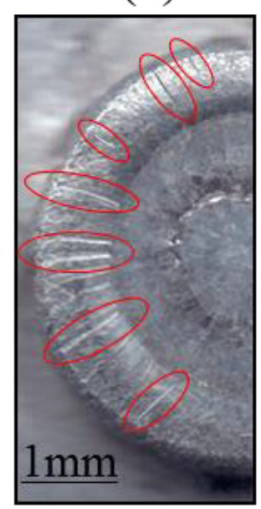

(b)

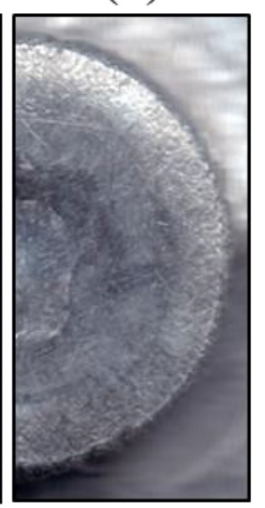

Fig. 18. Comparison of the bulged bottom for clinched joint at: (a) no pre-heating mode and (b) EAMC condition.

the five repetitions. The trendline of average values is fitted via an exponential function.

As plotted in Figure 19, thicker necks and smaller undercut dimensions were resulted in the EAMC. The $31 \%$ increase in maximum created $t_{N}$ and $13 \%$ decrease in maximum created $t_{U}$ for the $R_{C}$ value of 0.28 , compared with no pre-heating mode, were mainly originated from the material flow changes. It is worth noting that the joining 


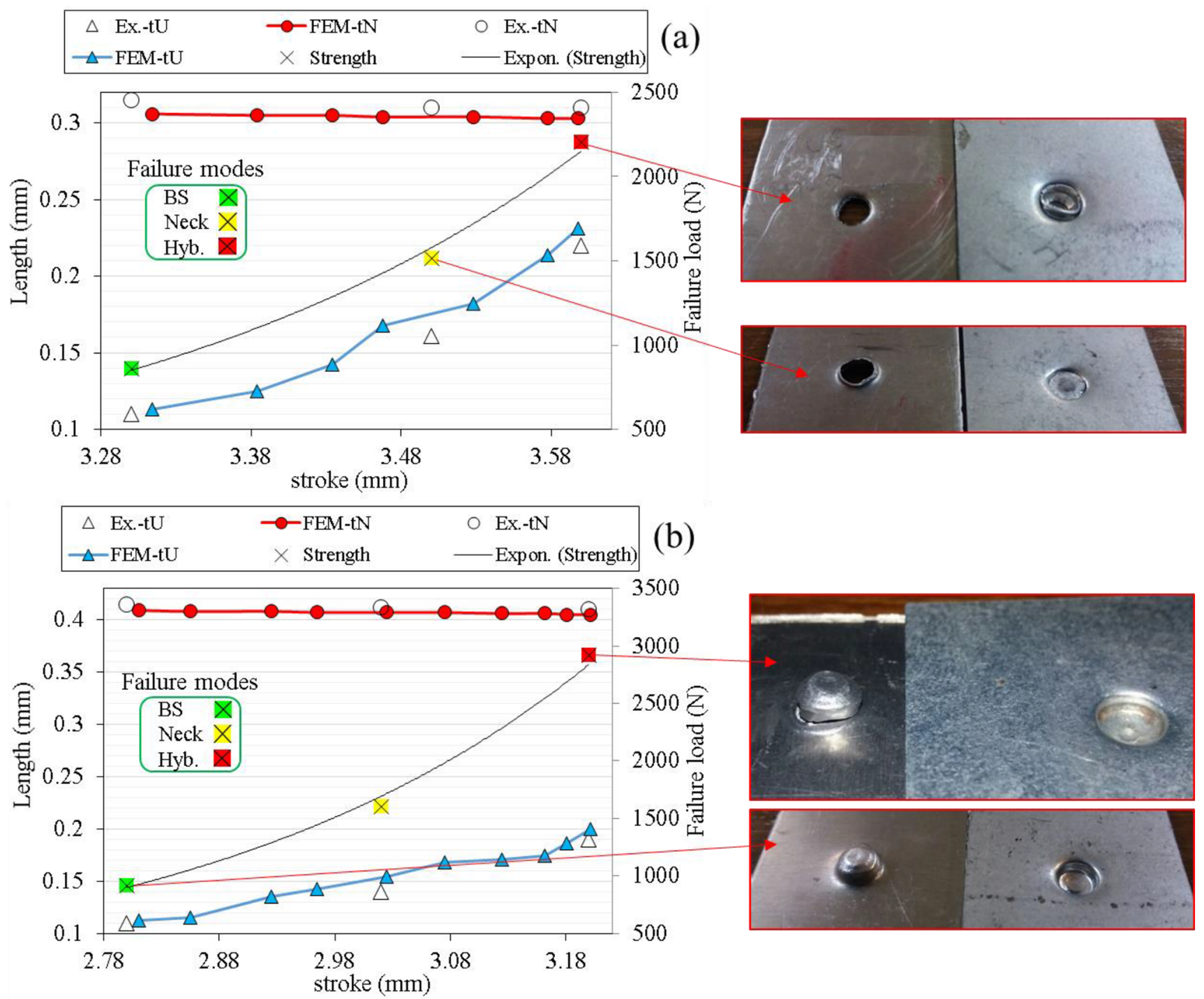

Fig. 19. Variation with punch stroke: (a) no pre-heating mode and (b) at EAMC condition.

range was extended by the applying pre-heating mode, at the smaller penetration depth $(3.2 \mathrm{~mm})$.

The increasing trend in failure loads was because of the increased interlock and negligible decrease of neck thickness through the punch stroke. At the less stroked penetration depth, the joints failed by button separation mode. When moderate strokes were employed, the joints failed by neck fracture mode. At the upper bound for strokes, the hybrid fracture mode occurred at both conditions. The hybrid failure modes consisted of two mechanisms including neck fracture and button separation [26]. In which the load-bearing capacity is a combination of shear and tensile strengths, so they can create higher strength clinched joints compared with fewer strokes.

\subsection{Comparison of EAMC with applied heating-assisted joining methods}

According to the reviewed papers investigated the heatingassisted mechanical clinching methods, mostly used similar sheets with low ductility characteristic including titanium, aluminum, and magnesium alloys. Lambiase [20] could enhance the tensile shear strength just to $1600 \mathrm{~N}$ in $\mathrm{MC}$ of pre-heated AA6082-T6 sheets. He used a heater gun (hardto-control relative to EAMC) that resulted in much heat loss in pre-heating duration time of $50 \mathrm{~s}$. Reich et al. [32] reported the strength loss in laser-assisted MC. However, they increased tool life by reducing the tool wear. Besides, Zhang et al. [31] reported that the tensile strength and fatigue strength were decreased in MC of TA1 via. postheating treatment in the furnace. Nevertheless, the plasticity and energy absorption of the joints were improved. On the other hand, Hahn et al. [29] could achieve to joint strength equal to $2100 \mathrm{~N}$ in inductionassisted MC of AZ31 sheets, where the sheets were failed to be clinched at RT. In addition, Zhang et al. [27] could reach to a $35 \%$ increase in resistance spot clinching at the electrical current of $20 \mathrm{kA}$, i.e. 40 times more than the current value used in proposed EAMC method in the present research. 
In present study, applying pre-heating operation, in addition to reducing forming load and increasing clinchability, resulted in a $32 \%$ increase in failure load. This enhancement was achieved only with a low-value electrical current compared with $[27,28]$, as well as the lower rate of heat loss than [20,30,31]. Besides, the $32 \%$ increase in failure load led to a limit far enough above the AWS recommended requirement for resistance spot welding of the $\mathrm{Al} / \mathrm{St}$ sheets which was computed $1400 \mathrm{~N}$ using equation (1).

\section{Conclusion}

The effects of the geometrical properties on section parameters, failure loads, and failure modes were investigated for the electrically-assisted mechanical clinching of AA6061-T6 aluminum to galvanized DP590 steel. From the experimental and numerical analysis using a 2-step coupled electrical-thermal-mechanical FE model, these can be concluded that:

- The newly defined parameter $R_{C}$ with the value of 0.28 caused the easiness of material flow obtained by a $5 \%$ increase in punch-anvil cavity volume. The reduced resistance to material flow created a more uniform strain distribution. In addition, the prolonged drawing phase for the $R_{C}$ value of 0.28 facilitated the radial material flow during upsetting and interlocking phases. As a result, it resulted in more than twice the interlock length compared with the no-chamfer punch.

- By the use of the EAMC process, the difference of flow stress between the two sheets was increased that affected the material flow. In which the anvil-sided material forced the upper sheet to flow in the reverse axial direction and restricted the radial material flow. Besides, the maximum forming load decreased by 30\%. As a result, the clinch-ability range was extended and the $31 \%$ increase in maximum $t_{N}$ and $13 \%$ decrease in maximum $t_{U}$ were achieved.

- By the use of the EAMC process, the surface of the bulged bottom was more continuous with reduced defects. This was confirmed numerically where the smaller magnitude of tensile stress at the bulged bottom was predicted compared with no pre-heating mode.

- Control the material flow using the defined parameter $R_{C}$ as well as the use of electrically-assisted pre-heating operation increased the joint strength by $32 \%$. The excellent failure load equal to $2922 \mathrm{~N}$ was achieved; far enough above the AWS recommended requirement for resistance spot welding of the $\mathrm{Al} / \mathrm{St}$ sheets calculated $1400 \mathrm{~N}$.

\section{References}

[1] www.A2Mac1.com

[2] A. Barimani-Varandi, The non-isothermal hot deep drawing of AA5083 aluminum alloy, Mech. Ind. 21, 112 (2020)

[3] A. Al-Mukhtar, Review of resistance spot welding sheets: processes and failure mode, Adv. Eng. Forum. Trans Tech Publ. 31-57 (2016)
[4] P.-C. Lin, S.-M. Lo, S.-P. Wu, Fatigue life estimations of alclad AA2024-T3 friction stir clinch joints, Int. J. Fatigue 107, 13-26 (2018)

[5] Z. Shen, X. Yang, Z. Zhang, L. Cui, T. Li, Microstructure and failure mechanisms of refill friction stir spot welded 7075T6 aluminum alloy joints, Mater. Des. 44, 476-486 (2013)

[6] Y. Zhao, H. Liu, Z. Lin, S. Chen, J. Hou, Microstructures and mechanical properties of friction spot welded Alclad 7B04-T74 aluminium alloy, Sci. Technol. Weld. Joining 19, 617-622 (2014)

[7] J. Aoh, P. Lin, Process development of FSW/FSSW on complex curvilinear surface components. AIDC Technical Report, 2009

[8] R.W. Manufacturers' Alliance, Resistance welding manual (American Welding Society, Miami, Florida, 2003)

[9] D. Li, A. Chrysanthou, I. Patel, G. Williams, Self-piercing riveting - a review, Int. J. Adv. Manufactur. Technol. 92, 1777-1824 (2017)

[10] https://www.tox-nz.com/

[11] L. Thies, Blechverbindung, Deutsches Reichspatent, 1897

[12] G. Dingfeld, Fastening engineering. 25 years of clinch technology - a process has shaped up nicely (25 Jahre Clinchtechnik-Ein Verfahren hat Sich Entwickelt), Konstruktion. 10, 47-49 (2006)

[13] T. Balawender, T. Sadowski, M. Kneć, Technological problems and experimental investigation of hybrid: clinched-adhesively bonded joint, Arch. Metall. Mater. 56, 438-446 (2011)

[14] R. Banham, The Ford century: Ford Motor Company and the innovations that shaped the world, Artisan Books, 2002

[15] B. Awiszus, U. Beyer, F. Riedel, M. Todtermuschke, Simulation based development of a clinch connection with plane surface of die side, Adv. Technol. Plactisity 584-585 (2008)

[16] J. Kim, C. Lee, S. Lee, D. Ko, B. Kim, Effect of shape parameters of tool on improvement of joining strength in clinching, Trans. Mater. Process. 18, 392-400 (2009)

[17] J. Mucha, The analysis of lock forming mechanism in the clinching joint, Mater. Des. 32, 4943-4954 (2011)

[18] Y. Abe, K. Mori, T. Kato, Joining of high strength steel and aluminium alloy sheets by mechanical clinching with dies for control of metal flow, J. Mater. Process. Technol. 212, 884-889 (2012)

[19] Y. Abe, S. Nihsino, K.-i. Mori, T. Saito, Improvement of joinability in mechanical clinching of ultra-high strength steel sheets using counter pressure with ring rubber, Proc. Eng. 81, 2056-2061 (2014)

[20] F. Lambiase, Clinch joining of heat-treatable aluminum AA6082-T6 alloy under warm conditions, J. Mater. Process. Technol. 225, 421-432 (2015)

[21] M.K.S. Atia, M.K. Jain, Die-less clinching process and joint strength of AA7075 aluminum joints, Thin-Walled Struct. 120, 421-431 (2017)

[22] M.-h. Wang, G.-q. Xiao, Z. Li, J.-q. Wang, Shape optimization methodology of clinching tools based on Bezier curve, Int. J. Adv. Manufactur. Technol. 94, 2267-2280 (2018)

[23] C.-J. Lee, J.-Y. Kim, S.-K. Lee, D.-C. Ko, B.-M. Kim, Design of mechanical clinching tools for joining of aluminium alloy sheets, Mater. Des. 31, 1854-1861 (2010)

[24] J.P. Varis, A novel procedure for establishing clinching parameters for high-strength steel sheet (2003) 
[25] J. Varis, Ensuring the integrity in clinching process, J. Mater. Process. Technol. 174, 277-285 (2006)

[26] L. Lei, X. He, T. Yu, B. Xing, Failure modes of mechanical clinching in metal sheet materials, Thin-Walled Struct. 144, 106281 (2019)

[27] Y. Zhang, H. Shan, Y. Li, J. Guo, Z. Luo, C.Y. Ma, Joining aluminum alloy 5052 sheets via novel hybrid resistance spot clinching process, Mater. Des. 118, 36-43 (2017)

[28] L.-W. Chen, M.-J. Cai, Development of a hot stamping clinching tool, J. Manufactur. Process. 34, 650-658 (2018)

[29] O. Hahn, Y. Tan, M. Schroeder, M. Horstmann, Thermally supported mechanical joining of magnesium components, Materials Science Forum. Trans Tech Publ, 2005, pp. $365-370$

[30] F. Lambiase, A. Di Ilio, A. Paoletti, Joining aluminium alloys with reduced ductility by mechanical clinching, Int. J. Adv. Manufactur. Technol. 77, 1295-1304 (2015)

[31] Y. Zhang, X. He, K. Zeng, L. Lei, F. Gu, A. Ball, Influence of heat treatment on mechanical properties of clinched joints in titanium alloy sheets, Int. J. Adv Manufactur. Technol. 91, 3349-3361 (2017)

[32] M. Reich, J. Osten, B. Milkereit, J. Kalich, U. Füssel, O. Kessler, Short-time heat treatment of press hardened steel for laser assisted clinching, Mater. Sci. Technol. 30, 1287-1296 (2014)

[33] P.-C. Lin, S. Lo, Development of friction stir clinching process for alclad 2024-T3 aluminum sheets, SAE Int. J. Mater. Manufactur. 9, 756-763 (2016)

[34] J.T. Carter, Method of Friction-Assisted Clinching. Google Patents, 2010

[35] H.-D. Nguyen-Tran, H.-S. Oh, S.-T. Hong, H.N. Han, J. Cao, S.-H. Ahn, D.-M. Chun, A review of electrically-assisted manufacturing, Int. J. Precis. Eng. Manufactur. Green Technol. 2, 365-376 (2015)

[36] W.A. Salandro, J.J. Jones, C. Bunget, L. Mears, J.T. Roth, Electrically assisted forming: Modeling and control, Springer, 2014

[37] A. Barimani-Varandi, S.J. Hosseinipour, Numerical and experimental study on the effect of forming speed in gradient warm deep drawing process, J. Solid Fluid Mech. 8, 51-66 (2018)

[38] A. Barimani-Varandi, S. Jamal Hosseinipour, Investigation of process parameters in production of cylindrical parts by gradient warm deep drawing, Modares Mech. Eng. 14 (2015)
[39] X. Han, S. Zhao, C. Liu, C. Chen, F. Xu, Optimization of geometrical design of clinching tools in clinching process with extensible dies, Proc. Inst. Mech. Eng. C 231, 3889-3897 (2017)

[40] C.-J. Lee, J.-Y. Kim, S.-K. Lee, D.-C. Ko, B.-M. Kim, Parametric study on mechanical clinching process for joining aluminum alloy and high-strength steel sheets, J. Mech. Sci. Technol. 24, 123-126 (2010)

[41] Y. Zhou, F. Lan, J. Chen, Influence of tooling geometric parameters on clinching joint properties for steel-aluminum hybrid car-body structures, 2010 3rd International Conference on Computer Science and Information Technology, 2010

[42] S. Coppieters, P. Lava, R. Van Hecke, S. Cooreman, H. Sol, P. Van Houtte, D. Debruyne, Numerical and experimental study of the multi-axial quasi-static strength of clinched connections, Int. J. Mater. Form. 6, 437-451 (2013)

[43] F. Lambiase, A. Di Ilio, Joining Aluminum with Titanium alloy sheets by mechanical clinching, J. Manufactur. Process. 35, 457-465 (2018)

[44] T. Kobayashi, Y. Mihara, Numerical simulation of nugget formation in spot welding, SIMULIA Community Conference, 2014

[45] F. Lambiase, A. Di Ilio, Damage analysis in mechanical clinching: Experimental and numerical study, J. Mater. Process. Technol. 230, 109-120 (2016)

[46] S. Coppieters, H. Zhang, F. Xu, N. Vandermeiren, A. Breda, D. Debruyne, Process-induced bottom defects in clinch forming: Simulation and effect on the structural integrity of single shear lap specimens, Mater. Des. 130, 336-348 (2017)

[47] B. Xing, X. He, Y. Wang, H. Yang, C. Deng, Study of mechanical properties for copper alloy $\mathrm{H} 62$ sheets joined by self-piercing riveting and clinching, J. Mater. Process. Technol. 216, 28-36 (2015)

[48] Z.-M. Su, P.-C. Lin, W.-J. Lai, J. Pan, Fatigue analyses of self-piercing rivets and clinch joints in lap-shear specimens of aluminum sheets, Int. J. Fatigue 72, 53-65 (2015)

[49] L. Kaščák, E. Spišák, Clinching as a non-standard method for joining materials of dissimilar properties, Zeszyty Naukowe Politechniki Rzeszowskiej. Mechanika 31-41 (2012)

[50] K. Mori, Y. Abe, T. Kato, Mechanism of superiority of fatigue strength for aluminium alloy sheets joined by mechanical clinching and self-pierce riveting, J. Mater. Process. Technol. 212, 1900-1905 (2012)

[51] W.F. Hosford, R.M. Caddell, Metal forming: mechanics and metallurgy, Cambridge University Press, 2011

Cite this article as: A. Barimani-Varandi, A.J. Aghchai, Electrically-assisted mechanical clinching of AA6061-T6 aluminum to galvanized DP590 steel: effect of geometrical features on material flow and mechanical strength, Mechanics \& Industry 21, 529 (2020) 